\title{
NF- $\kappa$ B and Matrix-Dependent Regulation of Osteopontin Promoter Activity in Allylamine-Activated Vascular Smooth Muscle Cells
}

\author{
E. Spencer Williams, ${ }^{1}$ Emily Wilson, ${ }^{2}$ and Kenneth S. Ramos ${ }^{3}$ \\ ${ }^{1}$ Department of Veterinary Physiology and Pharmacology, Texas A\&M University, College Station, TX, USA \\ ${ }^{2}$ Department of Medical Physiology, Texas A\&M University System Health Science Center, College Station, TX, USA \\ ${ }^{3}$ Department of Biochemistry and Molecular Biology, University of Louisville School of Medicine, Louisville, KY 40292, USA
}

Correspondence should be addressed to Kenneth S. Ramos, ksramo01@louisville.edu

Received 17 August 2011; Revised 9 October 2011; Accepted 9 October 2011

Academic Editor: Oren Tirosh

Copyright (C) 2012 E. Spencer Williams et al. This is an open access article distributed under the Creative Commons Attribution License, which permits unrestricted use, distribution, and reproduction in any medium, provided the original work is properly cited.

Repeated cycles of oxidative injury by allylamine in vivo induce a proliferative rat vascular (aortic) smooth muscle cell (vSMC) phenotype characterized by matrix-dependent enhancement of mitogenic sensitivity, changes in cell surface integrin expression, and osteopontin $(o p n)$ overexpression. Here, we show that constitutive and mitogen-stimulated NF- $\kappa \mathrm{B}$ DNA binding activity is enhanced in allylamine vSMCs. Matrix-specific changes in cellular Rel protein expression were observed in allylamine vSMCs. The NF- $\kappa$ B DNA binding element located at -1943 in the $5^{\prime}$-UTR strongly inhibited opn promoter activity in allylamine vSMCs, and this response was regulated by the extracellular matrix. Constitutive increases in opn promoter activity were only seen when allylamine cells were seeded on a fibronectin substrate, and this response was independent of the NF- $\kappa$ B DNA binding sequence within the regulatory region. Thus, NF- $\kappa \mathrm{B}$ functions as a critical regulator of the allylamine-induced proliferative phenotype in vSMCs.

\section{Introduction}

Atherosclerosis is a chronic inflammatory disease associated with thickening of the arterial wall and reduction in vessel lumen size. The atherosclerotic lesion consists of a mixture of immune cells, extracellular matrix, fatty deposits, and phenotypically modified vSMCs [1]. Injury of vSMCs produces atherogenic (i.e., activated) phenotypes characterized by increased proliferative and migratory activities and loss of differentiation [2]. These characteristics are replicated when blood vessels are subjected to viral, chemical, or physical injury in vivo [3-5], or when vSMCs are cultured in the presence of mitogens [6], or seeded at low densities on a growthpermissive fibronectin matrix [7]. The nature and extent of phenotypic modulation is subject to regulation since variable degrees of phenotypic drift are seen depending upon the nature of the stimulus and the culture conditions in vitro [8]. The finding that vSMCs isolated from atherosclerotic vessels express characteristics of the activated phenotype suggests that the atherosclerotic process involves reprogramming of vascular gene expression. This is comparable to the changes seen in vSMCs isolated from animals challenged chronically with allylamine $\left(\mathrm{CH}_{2}=\mathrm{CHCH}_{2} \mathrm{NH}_{2}\right)$, a primary amine metabolized within the vascular compartment to acrolein and hydrogen peroxide [9].

Repeated exposure of rats to allylamine induces vascular lesions of atherosclerotic morphology that arise from the injury caused by acrolein and hydrogen peroxide, byproducts of oxidative deamination within the vascular wall [10]. vSMCs are enriched in a copper-containing amine oxidase that catalyzes the metabolism of allylamine and mediates depletion of cellular glutathione, direct oxidant injury to the tunica media, and phenotypic modulation of vSMCs to less differentiated phenotypes. In vitro analysis of vSMCs isolated from allylamine-treated animals revealed disorganization of the contractile apparatus, increases in endoplasmic reticulum, and emergence of a prominent nucleolus [11]. These activated vSMCs acquire a significant proliferative advantage 
over vSMCs from control counterparts and exhibit enhanced phosphoinositide-3-kinase (PI-3-K) activity, secretion, and deposition of matrix proteins, and modulation of integrincoupled NF- $\kappa$ B signaling [12].

$\mathrm{NF}-\kappa \mathrm{B}$ is a dimeric transcription factor that resides in the cytoplasm in association with an inhibitory protein, $\mathrm{I} \kappa \mathrm{B}$. The dimer consists of members of the Rel protein family including RelA/p65, RelB, c-Rel, p50, and p52. In response to a positive stimulus, $\mathrm{I} \kappa \mathrm{B}$ is phosphorylated by $\mathrm{I}-$ $\kappa$-kinase $(\mathrm{IKK})$. Phosphorylation of $\mathrm{I} \kappa \mathrm{B}$ renders the protein susceptible to ubiquitination and proteolysis, allowing the $\mathrm{NF}-\kappa \mathrm{B}$ dimer to translocate to the nucleus and bind cisacting regulatory sequences [13]. The ability of NF- $\kappa \mathrm{B}$ to activate or repress target genes also depends on the phosphorylation status of Rel proteins [14]. NF- $\kappa$ B dimers of varying composition bind preferentially to distinct DNA sequences thus providing another point for differential regulation [15]. NF- $\kappa \mathrm{B}$ regulates genes involved in the inflammatory, mitogenic, and apoptotic response. Of interest is opn, a cytokine with prominent roles in immunity, bone remodeling, cancer, multiple sclerosis, arthritis, kidney dysfunction, and atherosclerosis. opn is sequestered in the extracellular matrix of atherosclerotic plaques and binds to $\alpha_{\mathrm{V}} \beta_{1}, \alpha_{\mathrm{V}} \beta_{3}, \alpha_{\mathrm{V}} \beta_{5}$, and $\alpha_{9} \beta_{1}$ integrin receptors on vSMCs $[16,17]$ to modulate proliferation, migration, and expression of inflammatory cytokines. The opn gene is regulated by upstream stimulatory factor 1 (USF1) and activator protein1 (AP-1) transcription factors [18], but to date a definitive role for NF- $\kappa \mathrm{B}$ has not been described. Detailed correlations between $o p n$ and atherosclerosis in humans [19, 20], and in animal models, have been reported [21].

We have previously described a central role for integrinextracellular matrix signaling in vSMC proliferation [12]. Evidence is presented here that extracellular matrix- and DNA sequence-specific changes in NF- $\kappa \mathrm{B}$ activity regulate $o p n$ promoter activity. These data indicate that NF- $\kappa \mathrm{B}$ participates in the regulation of vSMC phenotypes by oxidative chemical injury.

\section{Materials and Methods}

2.1. Materials. Allylamine (99\% pure) was purchased from Aldrich (Milwaukee, WI). Medium 199, trypsin, and antibiotic/antimycotic solution were purchased from Gibco (Grand Island, NY). [ $\left.{ }^{32} \mathrm{P}\right]$-ATP was purchased from NEN Radiochemicals (Grand Island, NY). NF- $\kappa$ B consensus oligonucleotide and T4 polynucleotide kinase were purchased from Promega (Madison, WI). Antibodies for Rel proteins, $\mathrm{I} \kappa \mathrm{B} \alpha, \mathrm{I} \kappa \mathrm{B} \beta$, and IKK were purchased from Santa Cruz Biotechnologies (Santa Cruz, CA). The antibody for phosphoserine was obtained from Zymed Laboratories Inc. (San Francisco, CA). Protein A-sepharose beads were obtained from Amersham Biosciences (Piscataway, NJ). Matrix-coated plates (BioCoat) were purchased from Becton Dickinson (Franklin Lakes, NJ). Nitrocellulose membranes were purchased from BioRad (Hercules, CA). Dura chemiluminescent substrate was purchased from Pierce (Rockford, IL). Kits for plasmid and RNA purification and DNase treat- ment were from Qiagen (Valencia, CA). The QuikChange Site-Directed Mutagenesis kit was from Stratagene (La Jolla, CA). Fugene 6 was from Roche (Indianapolis, IN). All other chemicals were purchased from Sigma Chemical Co. (St. Louis, MO).

2.2. Cell Culture. vSMCs were isolated by enzymatic digestion of aortas from 12 adult male Sprague-Dawley rats gavaged with allylamine $(70 \mathrm{mg} / \mathrm{kg})$ or 12 control rats gavaged with tap water for 20 days as described in detail previously [8]. Subcultures were prepared by trypsinization of primary cultures and maintained in Medium 199 supplemented with $10 \% \mathrm{FBS}$ and $2 \mathrm{mmol} / \mathrm{L}$ L-glutamine in $5 \% \mathrm{CO}_{2}: 95 \%$ air at $37^{\circ} \mathrm{C} . \mathrm{G}_{0}$ synchronization was accomplished by incubation of cell cultures for 72 hours in Medium 199 containing 0.1\% FBS as described.

2.3. Electrophoretic Mobility Shift Assay (EMSA). Nuclear extracts were prepared using standard methodologies, quick frozen in liquid nitrogen, and stored at $-80^{\circ} \mathrm{C}$. For EMSA, $5 \mu \mathrm{g}$ of nuclear protein was incubated with $\left[{ }^{32} \mathrm{P}\right]$-end-labeled $\mathrm{NF}-\kappa \mathrm{B}$ consensus oligonucleotide for 1 hour. End labeling of oligonucleotides was performed with T4 polynucleotide kinase and $\gamma\left[{ }^{32} \mathrm{P}\right]$ ATP. Binding reactions were performed in $0.25 \mathrm{x}$ HEGDK $(25 \mathrm{mmol} / \mathrm{L}$ HEPES pH 7.6, $1.5 \mathrm{mmol} / \mathrm{L}$ EDTA, $10 \%$ glycerol, $1 \mathrm{mmol} / \mathrm{L} \mathrm{DTT}, 0.5 \mathrm{~mol} / \mathrm{L} \mathrm{KCl}$ ) buffer supplemented with $1 \mathrm{mmol} / \mathrm{L}$ DTT, $20 \mu \mathrm{g}$ BSA, and $50 \mathrm{ng}$ poly-dIdC. After addition of loading dyes, reactions were electrophoresed on $7 \%$ nondenaturing polyacrylamide gels at $25 \mathrm{~mA}$ in $0.5 \mathrm{x}$ TBE $(0.045 \mathrm{~mol} / \mathrm{L}$ Tris, $0.045 \mathrm{~mol} / \mathrm{L}$ Boric acid, $0.001 \mathrm{~mol} / \mathrm{L}$ EDTA). Gels were dried and exposed to Kodak X-OMAT film with an intensifying screen for autoradiography at $-80^{\circ} \mathrm{C}$ for 48 hours.

2.4. SDS-PAGE and Western Blotting. Subconfluent cultures were rinsed with PBS and scraped. The pellet was

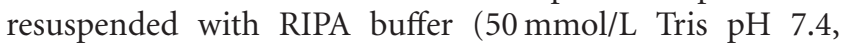
$150 \mathrm{mmol} / \mathrm{L} \mathrm{NaCl}, 1 \% \mathrm{NP}-40,10 \%$ sodium deoxycholate, $1 \mathrm{mg} / \mathrm{mL}$ leupeptin, $1 \mathrm{mg} / \mathrm{mL}$ aprotinin, $1 \mathrm{mg} / \mathrm{mL}$ pepstatin) and stored at $-20^{\circ} \mathrm{C}$. Three- $10 \mu \mathrm{g}$ of protein were diluted in sample buffer, boiled for 5 minutes, and loaded into a $7 \%$ denaturing polyacrylamide gel. Electrophoresis proceeded at $18-22 \mathrm{~mA}$ until tracking dyes reached the bottom. The gels were equilibrated in transfer buffer for 5 minutes and then transferred to nitrocellulose membranes for 9 hours at $20 \mathrm{~V}$ at $4^{\circ} \mathrm{C}$. Membranes were blocked in $5 \%$ milk in TBS $(0.1 \mathrm{~mol} / \mathrm{L}$ Tris $\mathrm{pH} 7.5,0.15 \mathrm{~mol} / \mathrm{L} \mathrm{NaCl})$ with $0.1 \%$ Tween (TTBS) for 18 hours then probed overnight with a 1 : 1000 dilution of rabbit primary antibody. After $6 \times 5$ min washes in TTBS, membranes were incubated for $4 \mathrm{hr}$ with a 1:25000 dilution of goat anti-rabbit IgG conjugated to horseradish peroxidase (HRP). Following another series of washes, membranes were incubated for 5 minutes in a $1: 2$ dilution of chemiluminescent substrate and then visualized for 30 seconds to 2 minutes on Kodak X-OMAT film.

2.5. Immunoprecipitation. Twenty five $\mu \mathrm{g}$ of protein was incubated overnight at $4^{\circ} \mathrm{C}$ with $1 \mu \mathrm{g}$ of antibody against 
IKK. Fifty $\mu \mathrm{L}$ of a $50 \%$ slurry in TE $(10 \mathrm{mmol} / \mathrm{L}$ Tris, $1 \mathrm{mmol} / \mathrm{L}$ EDTA pH 8.0) of protein A-sepharose was added to each immunoprecipitation reaction, and agitated for 4 hours at room temperature. The sepharose beads were pelleted and washed three times with TBS. Pellets were resuspended in Laemmli sample buffer and boiled for 5 minutes. After sepharose, beads were pelleted, $10 \mu \mathrm{L}$ of supernatant was loaded for SDS-PAGE.

2.6. Synthetic Oligonucleotides. Following examination of published sequences for mouse c-Ha-ras promoter, rat opn promoter, and rat matrix metalloproteinase-9, oligonucleotides corresponding to NF- $\kappa \mathrm{B}$ binding domains in these promoters were synthesized. The Genbank accession numbers and sequences used for each are shown in Table 1.

2.7. Generation of opn Promoter Constructs. The full-length rat opn promoter was provided by Dr. A. Ridall (UT Health Science Center, Houston, TX). 2094 base pairs were ligated into pGL2-basic using NheI and XhoI restrictions sites. This construct was dubbed 2094 rOPNpr and sequential deletions generated beginning at 1157 (1157 rOPNpr), 672 (672 rOPNpr), and 127 (127 rOPNpr), respectively. MatInspector v2.2 (available at http://www.generegulation.de/) identified a vitamin D response element (VDRE), as well as AP-1, $\mathrm{NF}-\kappa \mathrm{B}$, and USF1 transcription factor binding sites within the promoter. Site-directed mutagenesis of each of these sites was performed using Stratagene's QuikChange Kit per manufacturer's specifications. Following high-fidelity PCR, the template was digested with DpnI endonuclease to cleave methylated DNA and multiple clones sequenced for verification of mutations (Table 2).

2.8. Transfections. vSMCs were seeded at a density of $4 \times 10^{4}$ cells per well in a 12-well plate and allowed to recover for $8 \mathrm{~h}$ before transfection with luciferase constructs and a $\beta$ gal-expressing plasmid at a ratio of $1.5: 1.0 \mu \mathrm{g}$. Plasmids were mixed at a ratio of $6 \mu \mathrm{L}$ to $1 \mu \mathrm{g}$ DNA in serum-free Medium 199 and added to the cultures for $36 \mathrm{~h}$. Wells were rinsed with PBS and harvested using a lysis buffer included in Tropix's Galacto-Light Reporter Assay Kit (Foster City, CA). Lysates were frozen until analysis. Twenty-five $\mu \mathrm{L}$ of lysate was pipetted into two 96-well plates and either combined with $80 \mu \mathrm{L}$ of a luciferin working solution to measure luminescence in a BMG's Fluostar OPTIMA plate reader, or $70 \mu \mathrm{L}$ of Tropix's $\beta$-gal reagent. $\beta$-gal samples were incubated for $1 \mathrm{hr}$ before the addition of $100 \mu \mathrm{L}$ of accelerator solution for measurement using an OPTIMA plate reader.

2.9. Statistics. All other statistical relationships were examined by ANOVA and Fisher's least significant difference, unless otherwise noted. Statistical significance was assigned at the $P<0.05$ level.

\section{Results}

Repeated cycles of oxidative injury by allylamine induce a proliferative vSMC phenotype $[11,12]$. To evaluate the
TABLE 1

\begin{tabular}{lc}
\hline Mouse H-ras & 5' GGG GGT GGG GTC CTC CCT TTT 3' \\
(AF268311) & 3' CCC CCA CCC CAG GAG GGA AAA 5' \\
Rat opn & 5' GAT TTG TGG AAT TTC CCT GCA 3' \\
(AF017274) & 3' CTA AAC ACC TTA AAG GGA CGT 5' \\
Rat MMP-9 & 5' GGG GTT A GG GGG TTC CCC GTG 3' \\
(AJ428366) & 3' CCC CAA TCC CCC AAG GGG CAC 5' \\
\hline
\end{tabular}

stability of the activated vSMC phenotype induced by allylamine, the proliferation rates of control and allylamine cells during serial propagation in vitro were compared in cultures seeded at equal densities. Significant differences in proliferation were seen in both primary and secondary cultures of vSMCs isolated from allylamine-treated animals compared to controls (Figure 1). The proliferative vSMC phenotype induced by allylamine was sustained for up to 25 passages in serial culture. The proliferation of vSMCs of control and allylamine cells in primary culture was more restricted than in cultures during the $3 \mathrm{rd}$ and 25 th passage. This difference may be accounted for by the selection of more proliferative phenotypes during cell culture or partial shifts toward proliferative phenotypes.

The proliferative phenotype induced by allylamine is characterized by enhanced secretion and deposition of matrix proteins, and modulation of integrin-coupled NF- $\kappa \mathrm{B}$ signaling [12]. To evaluate the role of NF- $\kappa \mathrm{B}$ in the regulation of the proliferative allylamine phenotype, experiments were conducted to examine a time course of NF- $\kappa \mathrm{B}$ binding activity to a consensus sequence in quiescent vSMC subcultures following mitogenic stimulation. Cells were synchronized by serum restriction and stimulated into growth with $10 \%$ serum for up to 5 hours. The profile of NF- $\kappa \mathrm{B}$ binding activity in allylamine-modified vSMCs was different from control counterparts, with 3 distinct complexes detected at different times (Figure 2(a)). Constitutive NF- $\kappa \beta$ binding activity was enhanced in allylamine-modified vSMCs relative to controls. Mitogenic stimulation induced DNA binding activity as early as $0.5 \mathrm{hr}$ in both cell types, but the predominance of individual complexes over time was phenotypespecific. Increased DNA binding activity was observed at all times in allylamine cells.

Because nuclear translocation of NF- $\kappa \mathrm{B}$ is known to be dependent upon the degradation of $\mathrm{I} \kappa \mathrm{B}$ proteins [13], experiments were conducted next to evaluate steady-state levels of $\mathrm{I} \kappa \mathrm{B} \alpha$ and $\mathrm{I} \kappa \mathrm{B} \beta$ across the full synchronization and cell cycle transition regimen. The relative abundance of $\mathrm{I} \kappa \mathrm{Bs}$ was not affected by growth factor deprivation since comparable protein levels were detected in synchronized cultures, as well as 0.5 hours after mitogen addition (Figure 2(b)). Degradation of $\mathrm{I} \kappa \mathrm{B} \alpha$ was observed in the activated VSMC phenotype within $1 \mathrm{hr}$ of serum stimulation, a response that peaked by $2 \mathrm{hr}$ and began to subside by $3 \mathrm{hr}$. Modest reductions in $\mathrm{I} \kappa \mathrm{B} \alpha$ were observed in control vSMCs, showing that early activation of NF- $\kappa \mathrm{B}$ in response to mitogenic stimulation is a characteristic feature of the allylamine phenotype (Figure 2(b)). No degradation of $\mathrm{I} \kappa \mathrm{B} \beta$ was observed in either cell type at any of the time points 
TABLE 2: Site-directed mutagenesis of opn promoter constructs.

\begin{tabular}{lll}
\hline Binding site & & Sequence \\
\hline \multirow{2}{*}{ VDRE } & Original & $5^{\prime}$ CCTGGAAGGGTCATATGGTTCAGCTCCGAGG 3' \\
& Mutated & $5^{\prime}$ CCTGGAAtcGTtcTATGGaTCtGCTCCGAGG 3' \\
AP-1 & Original & $5^{\prime}$ TCGTGTTGAGTCATTCCTGTGGGC 3' \\
& Mutated & $5^{\prime}$ TCGTGTTacaTCATTCCTGTGGGC 3' \\
NF- $\kappa$ B & Original & $5^{\prime}$ AGGATTTGTGGAATTTCCCTGCACAGC 3' \\
& Mutated & $5^{\prime}$ AGGATTTGaaGAATaaCaCTGCACAGC 3' \\
USF1 & Original & $5^{\prime}$ AAACAAACTCATGTGGGTGTCGTGCTT 3' \\
& Mutated & $5^{\prime}$ AAACAAACTCAaaTGGGTGTCGTGCTT 3' \\
\hline
\end{tabular}

Transcription factor binding sites were mutated using Stratagene's QuikChange and Site-Directed Mutagenesis Kit. Binding sites are underlined, and mutated bases shown in lowercase.

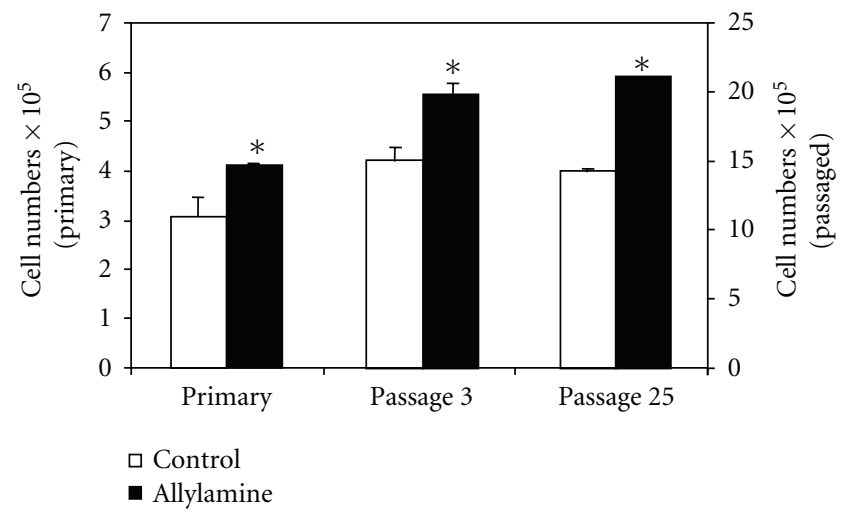

FIGURE 1: Stability of the allylamine-activated vascular smooth muscle cell phenotype during serial propagation in vitro. Vascular smooth muscle cells were isolated from control and allylaminetreated rats and established in primary culture or passaged for up to 25 passages using established procedures. Cells were seeded at a density of 150 cells $/ \mathrm{mm}^{2}$ and incubated with $10 \%$ fetal bovine serum for four days in culture. The results shown represent the average number of cells in 5-7 replicate dishes during primary culture or at passages 3 and 25 for the two cell types. Similar patterns were observed in 3 separate experiments. The results show that allylamine cells exhibited a proliferative advantage that was sustained for multiple passages in vitro.

examined. The degradation of $\mathrm{I} \kappa \mathrm{B}$ proteins is preceded by phosphorylation by the I $\kappa \mathrm{B}$ kinases, IKK $\alpha$ and IKK $\beta$ [13]. Analysis of immunoprecipitated IKK in cells seeded on a plastic substrate revealed slightly increased serine phosphorylation in allylamine-modified vSMCs irrespective of growth status (Figure 2(c)). Two immunoreactive bands were detected, indicating recognition of both IKK $\alpha$ and IKK $\beta$ isoforms (not shown).

We have previously demonstrated that NF- $\kappa \mathrm{B}$ DNA binding activity is differentially modified by the extracellular matrix [22]. To evaluate the possibility that ECM-dependent changes in NF- $\kappa$ B DNA binding activity were related to Rel protein expression, control and allylamine-modified vSMCs were seeded on plastic, collagen I, or fibronectin, and protein expression was determined by SDS-PAGE and Western blotting (Figure 3). The abundance of RelA/p65 was influenced by matrix and cellular phenotype, with reductions in band intensity observed in allylamine cells seeded on plastic or fibronectin, but not collagen I. A second immunoreactive band at approximately $45 \mathrm{kDa}$ was detected exclusively in allylamine-modified vSMCs on all matrices, with signal intensity being most prominent on plastic. The levels of RelB protein were slightly lower in allylamine cells seeded on all substrates, and as with p65, this reduction was most pronounced on plastic. c-Rel and p52 expression increased in allylamine cells seeded on plastic or collagen I but decreased slightly on fibronectin. In contrast, p50 expression was elevated in allylamine cells seeded on plastic or collagen I but remained unchanged when cells were seeded on fibronectin.

Phenotype-specific changes in the prevalence of Rel proteins may translate into variable composition of NF- $\kappa \mathrm{B}$ dimers. Such alterations may influence the profile of transcriptional regulation since different dimers may preferentially recognize different target sequences. To test this concept, NF- $\kappa \mathrm{B}$ binding elements from four different promoters were used to evaluate binding activity in nuclear extracts from control and allylamine vSMCs seeded on plastic. Up to four major binding protein complexes could be identified, two of which were conserved across all of the NF- $\kappa$ B binding sequences examined (Figure 4 ). With the exception of proteins bound to the NF- $\kappa \mathrm{B}$ sequence from the rat matrix metalloproteinase-9 (MMP-9) promoter, band intensities were higher in nuclear extracts from allylamineactivated vSMCs compared to controls, indicating a higher degree of NF- $\kappa \mathrm{B}$ activation. The intensity of the two fastermobility complexes ( $\mathrm{C} 3$ and $\mathrm{C} 4$ ) was sequence specific, with strong binding observed to the NF- $\kappa \mathrm{B}$ consensus and c-Haras sequences.

Enhanced expression of opn mRNA and protein characterizes the allylamine phenotype [23]. Because increased $\mathrm{NF}-\kappa \mathrm{B}$ binding to the $o p n$ promoter may contribute to differential gene regulation, experiments were conducted next to evaluate $o p n$ promoter activity in control and allylamine vSMCs. A schematic for serial deletions is shown in Figure 5(a). Activation of luciferase reporter constructs was observed in both cell types, with considerably higher activities seen upon progressive deletion of upstream sequences down to $572 \mathrm{bp}$ (Figure 5(b)). Thus, inhibitory sequences located between (2094 and 1157) and (1157 and 672) appear 


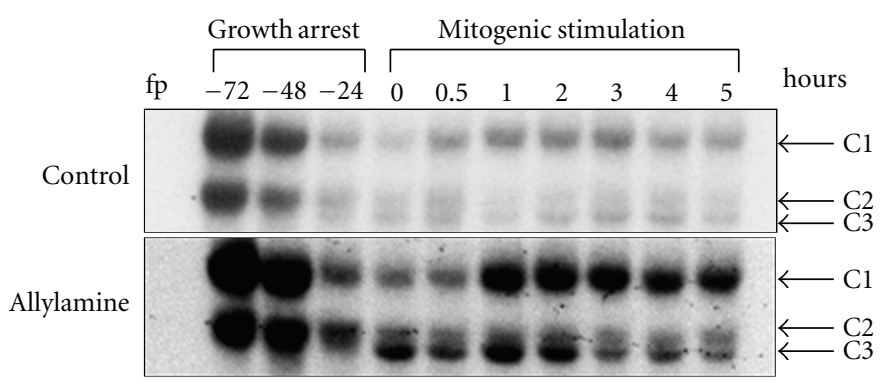

(a)

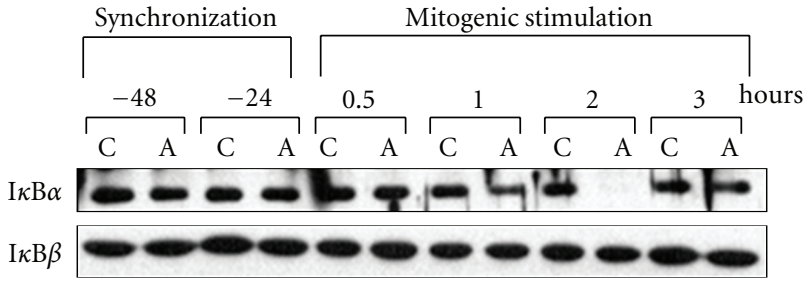

(b)

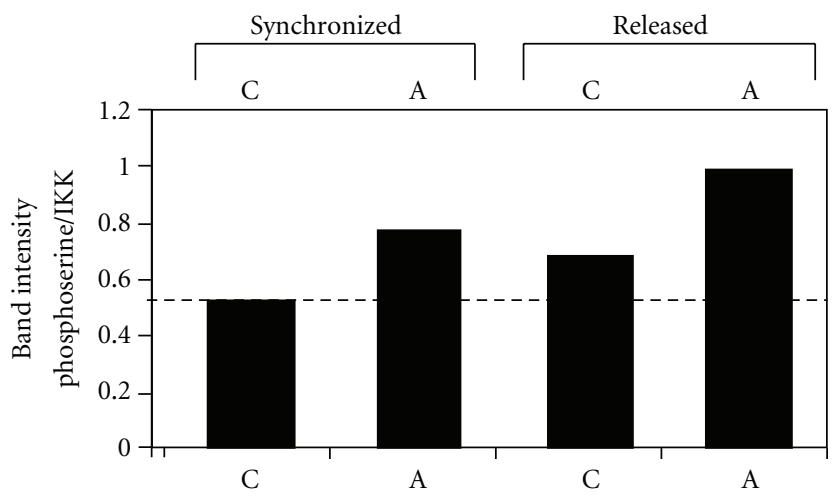

(c)

Figure 2: Activation of NF- $\kappa$ B signaling in allylamine cells. Panel (a) shows NF- $\kappa$ B binding activity in control and allylamine cells over the course of a synchronization and mitogenic stimulation cycle. Cells were seeded at equivalent densities on plastic tissue culture dishes and nuclear extracts collected at multiple time points as noted. EMSA were performed using end-labeled NF- $\kappa \mathrm{B}$ consensus oligonucleotide as a probe. Arrows denote the major NF- $\kappa$ B binding complexes identified. Similar results were seen in 2 independent experiments. $\mathrm{C}_{\#}$ denotes individual complexes. Panel (b) shows $\mathrm{I} \kappa \mathrm{B} \alpha$ and $\mathrm{I} \kappa \mathrm{B} \beta$ protein levels in control and allylamine cells over the course of a synchronization and mitogenic stimulation cycle. Cells were seeded at equivalent densities and serum restricted for $72 \mathrm{hr}$ to synchronize in $\mathrm{G}_{0}$, and then released into growth by the addition of $10 \%$ fetal bovine serum. Crude protein extracts were harvested at various times after addition of complete medium. Protein extracts were electrophoresed, electroblotted onto nitrocellulose, and probed for each I $\kappa$ B. Similar results were observed in 3 separate experiments. C: control; A: allylamine. Panel (c) shows serine phosphorylation levels of immunoprecipitated IKK $\alpha$ and IKK $\beta$ in control and allylamine cells. Immunoprecipitated IKK $\alpha / \beta$ was electrophoresed and transferred onto two nitrocellulose membranes and blocked overnight in $5 \%$ milk. One membrane was probed for $\mathrm{IKK} \alpha / \beta$, and the other for phosphoserine, followed by incubation with horseradish peroxidase- (HRP-) labeled secondary. Membranes were then incubated with chemiluminescent substrate and visualized using the KODAK Image Station. Densitometry was performed using Kodak 1 D Image Software. $\square$ : control, $\square$ : allylamine.

to significantly repress promoter activity in control and allylamine vSMCs. Promoter activity was completely lost in the minimal -127 promoter construct, and in all instances, promoter activity was considerably lower in allylamine cells compared to controls.

Examination of sequences between -2094 and -1157 revealed putative cis-acting elements for AP- $1, \mathrm{NF}-\kappa \mathrm{B}$ and USF, as well as the well-characterized VDRE. To evaluate the relative contribution of these elements, the inducibility of mutant promoter constructs generated by site-directed mutagenesis was examined (Figure 5(c)). In control cells, disruption of any one of the elements significantly reduced luciferase activity (Figure 5(d)), implicating these elements in positive regulation of opn promoter activity. Interestingly, in allylamine cells only mutation of the VDRE reduced promoter activity, while mutation of AP-1 was inert, and mutation of NF- $\kappa \mathrm{B}$ and USF binding sites returned transcriptional activity to full-length control levels. These results suggest that the $o p n$ promoter is under negative regulation by $\mathrm{NF}-\kappa \mathrm{B}$ and USF.
Lastly, the influence of a collagen I or fibronectin matrix on $o p n$ promoter activity was examined. The pattern of $o p n$ promoter activity was influenced by the matrix on which the cells were seeded with no changes seen between allylamine and control cells when cells were seeded on collagen (a nonpermissive matrix), and marked increases in allylamine cells over control cells when cells were seeded on fibronectin (a proliferation-permissive matrix), Figure 6(a). Deletion of the NF- $\kappa \mathrm{B}$ binding site slightly decreased promoter activity in control cells but increased promoter activity in allylamine cells seeded on collagen I. The positive regulatory influence of fibronectin on opn promoter activity was not influenced by mutation of the NF- $\kappa$ B binding site (Figure 6(b)).

\section{Discussion}

Allylamine injury induces vascular lesions in the rat aorta that resemble those seen in atherosclerotic vessels [24]. This response involves accumulation of oxidative byproducts 

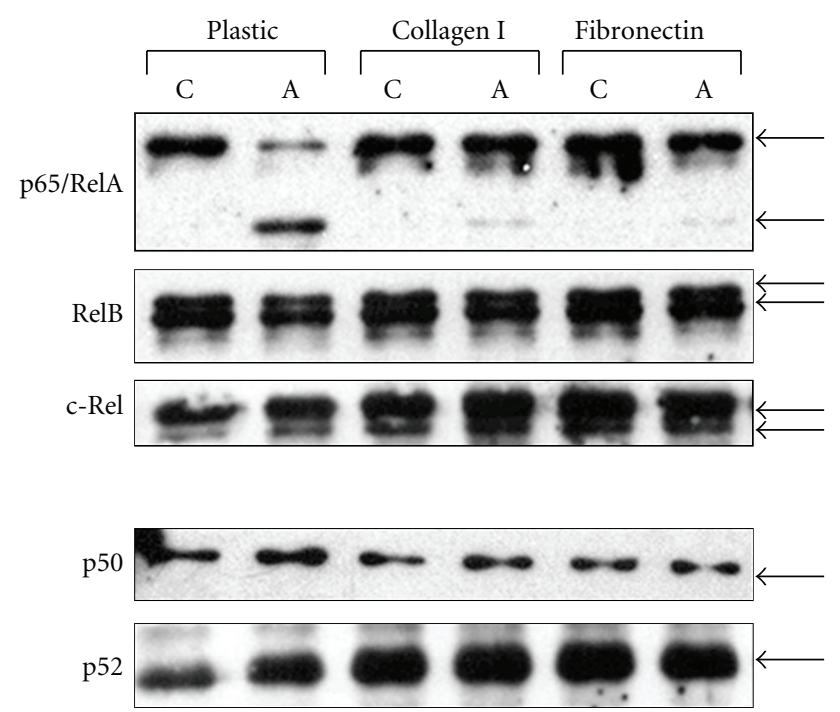

FIgURE 3: Expression of Rel proteins in control and allylamine cells seeded on plastic, collagen I, fibronectin, and laminin. Protein extracts from cells at $80 \%$ confluence were electrophoresed in a $7 \%$ denaturing polyacrylamide gel, transferred onto nitrocellulose, and blocked overnight in $5 \%$ milk in TBS with $0.1 \%$ Tween. Membranes were probed overnight followed by incubation with horseradish peroxidase-labeled secondary antibody for 4 hours and then incubated with 1:2 chemiluminescent substrate: TTBS for 5 minutes, followed by visualization through autoradiography. Similar results were seen in three separate experiments. C: control; A: allylamine.

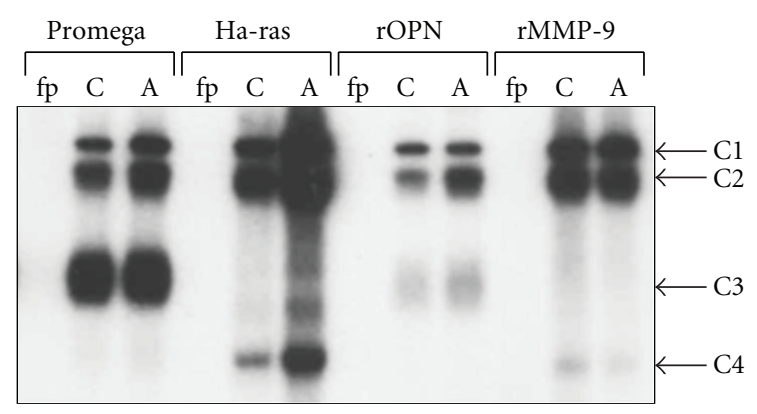

FIGURE 4: DNA binding activity in control and allylamine vSMCs to a panel of $\mathrm{NF} \kappa \mathrm{B}$ binding sequences. Nuclear extracts were subjected to EMSA against NF- $\kappa \mathrm{B}$ binding domains from several promoters (Ha-ras, rOPN, and rMMP-9), as well as a consensus oligo (Promega). Gels were dried and exposed to film for 48 hours at $-80^{\circ} \mathrm{C}$ with intensifying screen. Arrows denote major NF- $\kappa \mathrm{B}$ binding complexes identified. C: control; a: allylamine. Similar results were seen in multiple experiments.

within the vascular compartment, depletion of cellular glutathione, and activation of redox signaling $[10,25,26]$. The activated aortic vSMC phenotype induced by allylamine is stable suggesting that reprogramming of proliferative control contributes to phenotypic transition. Genomic reprogramming in vSMCs isolated from allylamine-injured vessels may involve alterations in NF- $\kappa \mathrm{B}$ signaling since NF- $\kappa$ B DNA protein binding is markedly enhanced. These findings parallel the molecular alterations seen in vSMCs isolated from atherosclerotic lesions [27, 28], and during the chronic hyperproliferative response to inflammation [28]. The present studies detail the molecular basis of NF- $\kappa \mathrm{B}$ dysregulation in allylamine vSMCs.

Disruption and remodeling of the vessel wall matrix is a pivotal process in atherogenesis where expression of activated vSMC phenotypes correlates with disruption of the basal lamina by macrophage metalloproteinases [29]. As the process of phenotypic modulation progresses, activated vSMCs change the relative composition of the extracellular matrix [30]. Collagen I becomes a large component of the matrix [31], as does fibronectin, a protein which promotes dedifferentiation of vSMCs within the lesion [32]. Previous data from this laboratory indicate that collagen I restricts the ability of allylamine-activated cells to proliferate, while cells seeded on plastic or fibronectin continue to grow at faster rates than controls [22]. Collagen I may elicit a reduction in proliferative activity through changes in p21 and cyclin D1 expression [33], while fibronectin mediates increases in cellular proliferation. The underlying mechanisms that translate reciprocal interactions between integrins and extracellular matrix proteins to transcriptional responses remain to be fully elucidated. In healthy vessels, matrix interactions protect against hyperproliferation of vSMCs, while in injured vessels, as the composition of the matrix changes, integrin-coupled NF- $\kappa \mathrm{B}$ activation and function is subject to significant modulation.

Matrix-dependent alterations in Rel protein expression were noted in allylamine vSMCs compared to controls, suggesting that NF- $\kappa \mathrm{B}$ dimers in allylamine vSMCs at any given point differ from those in controls. Because each dimer may preferentially interact with a different subset of DNA domains [15], shifts in Rel protein expression may result in differential modulation of gene expression. This appears to be the case since differences in NF- $\kappa$ B DNA binding activity were observed for different promoters, and opn promoter activity was differentially regulated in allylamine cells. Shifts in dimer prevalence have been described during B-cell differentiation leading to altered transcriptional activation of the immunoglobulin $\kappa$ light chain [34].

Progressive deletion analysis of the opn promoter uncovered strong repressor sequences within the promoter in vSMCs irrespective of phenotype. While the cis-acting elements responsible for gene regulation remain to be firmly established, several important findings were made. Notable differences between the two cellular phenotypes include (1) the activity of the opn promoter in allylamine cells was considerably lower than in control cells; (2) mutation of NF- $\kappa \mathrm{B}, \mathrm{AP}-1$, USF-1, and VDRE elements significantly reduced luciferase activity in control cells, while in allylamine cells only mutation of VDRE exerted a negative effect; (3) mutation of NF- $\kappa \mathrm{B}$ and USF binding sites in allylamine cells restored transcriptional activity to full-length control levels. Together, these findings suggest that opn promoter activity in allylamine cells is under negative control, possibly by NF- $\kappa$ B and USF-1 transcription factors. In fact, deletion of the NF- $\kappa \mathrm{B}$ binding site slightly decreased promoter activity in control cells seeded on collagen I but did not affect the 


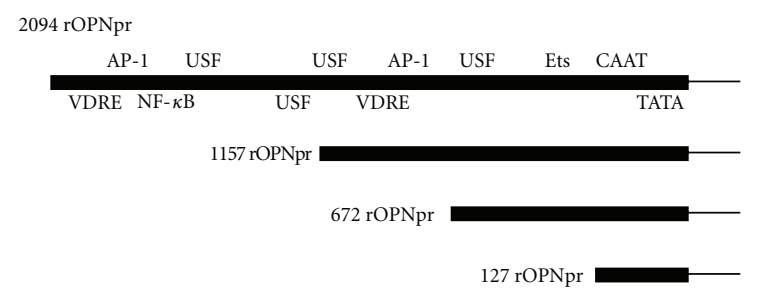

(a)

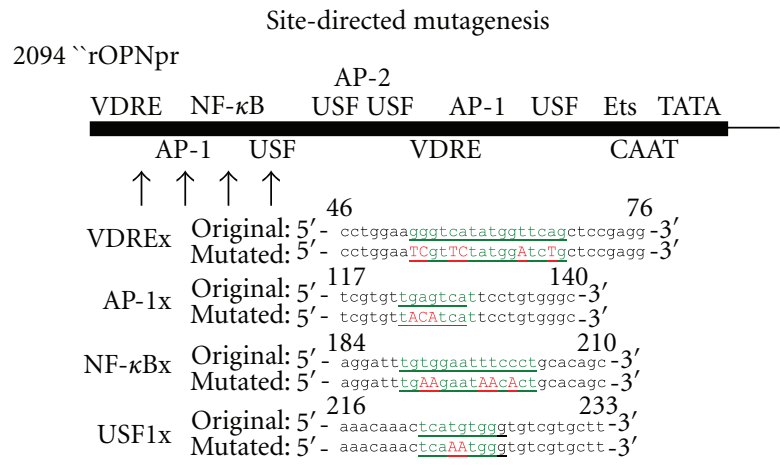

(c)

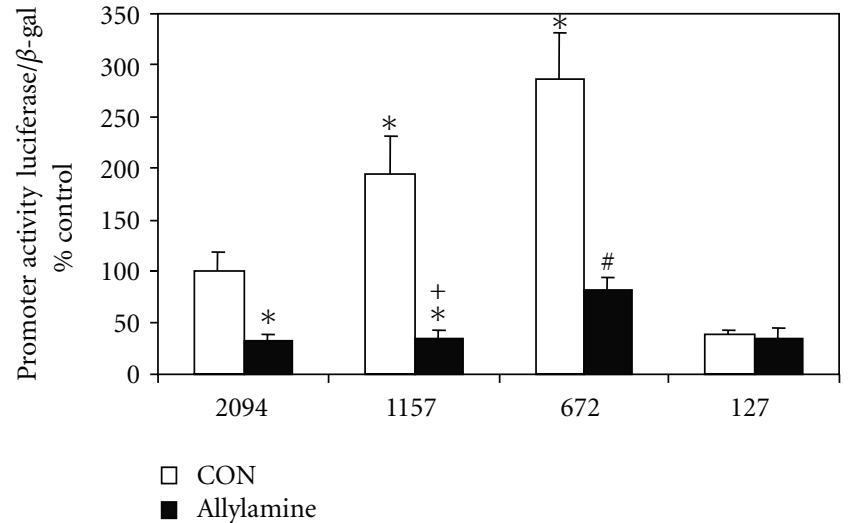

(b)

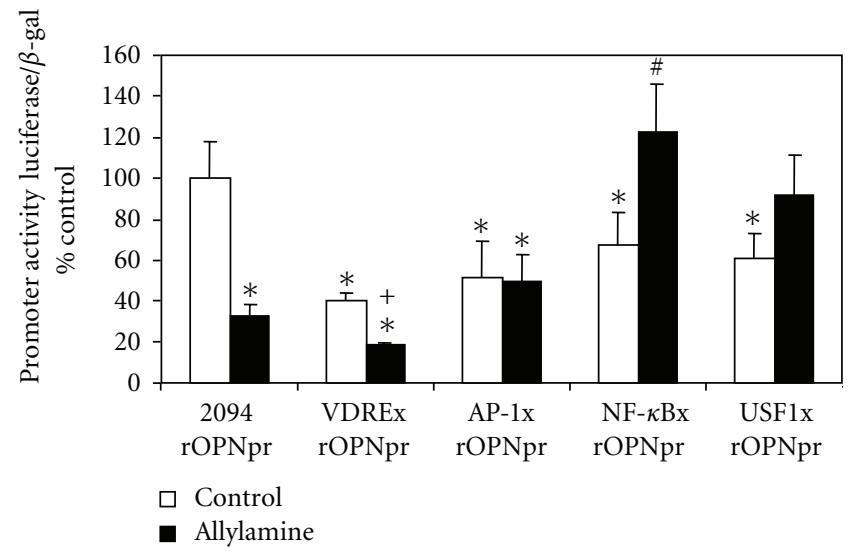

(d)

Figure 5: Profiles of osteopontin promoter activity in control and allylamine-activated vascular smooth muscle cells. Panel (a) shows a schematic representation of the rat osteopontin promoter, cis-acting elements within the full-length promoter, and several deletions thereof. Panel (b) shows a comparison of osteopontin promoter activity in control and allylamine cells. Control and allylamine cells were seeded at equivalent densities and allowed to recover for 8 hours. Cultures were then transfected with the rat osteopontin promoter in pGL2-basic, a luciferase vector, or a deletion thereof ( $1157 \mathrm{rOPNpr}, 672 \mathrm{rOPNpr}, 329 \mathrm{rOPNpr}$, and $129 \mathrm{rOPNpr}$ ). Also included as a control was $\beta$ galactosidase, to allow normalization of luciferase signal. $\square$ : control, $\mathbf{\square}$ : allylamine. $*$ indicates significant difference from 2094 rOPNpr in control, + indicates significant difference from 1157 rOPNpr in control, \# indicates significant difference from 657 rOPNpr in control $(P<0.05)$. Panel $(c)$ identifies mutants generated site-directed mutagenesis of the rat osteopontin promoter on activity profiles in control and allylamine cells. Several sites were identified through computerized examination and mutated using Stratagene's QuikChange SiteDirected Mutagenesis Kit. Alterations in each element are denoted by a capital letter. Panel (d) shows osteopontin promoter activity in control and allylamine cells after site-directed mutagenesis. Control and allylamine cells were seeded at equivalent densities and allowed to recover for 8 hours. Cultures were transfected with the rat osteopontin promoter (rOPNpr) in a luciferase vector, or a vector in which a cis-acting element has been mutated through site-directed mutagenesis. These mutants are denoted VDREx rOPNPr, AP-1x rOPNpr, NF- $\kappa$ Bx rOPNpr, USF1x rOPNpr, USF2x rOPNpr, and USF3x rOPNpr. $\square$ : control, $\square$ : allylamine. $*$ indicates significant difference from 2094 rOPNpr in control, + indicates significant difference from VDREx rOPNpr in control, \# indicates significant difference from NF- $\kappa$ Bx rOPNpr in control $(P<0.05)$. Similar results were seen in two separate experiments.

positive regulatory influence of fibronectin on promoter activity, indicating that NF- $\kappa \mathrm{B}$ may function as a positive or negative effector on $o p n$ promoter activity depending on phenotype.

Of note was the finding that opn promoter activity is influenced by the extracellular matrix on which the cells are seeded, with collagen exerting a repressor effect on promoter activity, and fibronectin affording a selective advantage to allylamine cells. This pattern of promoter activity parallels the proliferation and Rel protein expression profiles of control and allylamine cells, suggesting that the extracellular matrix dictates patterns of NF- $\kappa \mathrm{B}$ and $o p n$ signaling in allylamine cells. Thus, signaling through integrin receptors bound to fibronectin participate in the regulation of opn promoter activity in allylamine cells. This is consistent with the upregulation of $\alpha_{\mathrm{V}} \beta 3$ in allylamine cells seeded on a permissive matrix [23]. Regulation of opn expression in cells seeded on fibronectin does not seem to involve the NF- $\kappa \mathrm{B}$ binding site located at -1943 , while repression of promoter activity on collagen I may be partially accomplished through this NF- $\kappa \mathrm{B}$ element. The ability of fibronectin to induce dedifferentiation of vSMCs has been well documented [32, 35 ], as well as its ability to induce expression of opn in cultured vSMCs. 


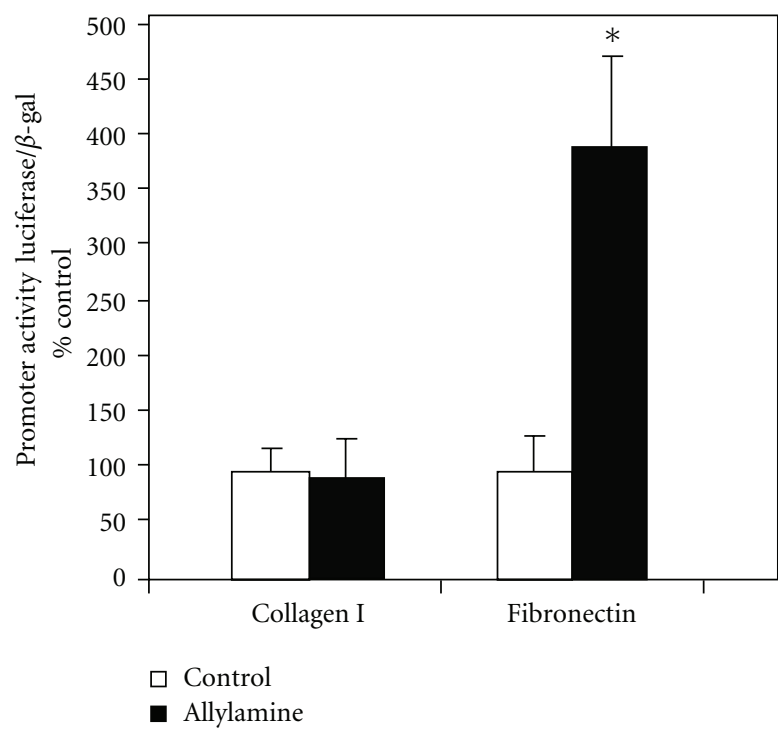

(a)

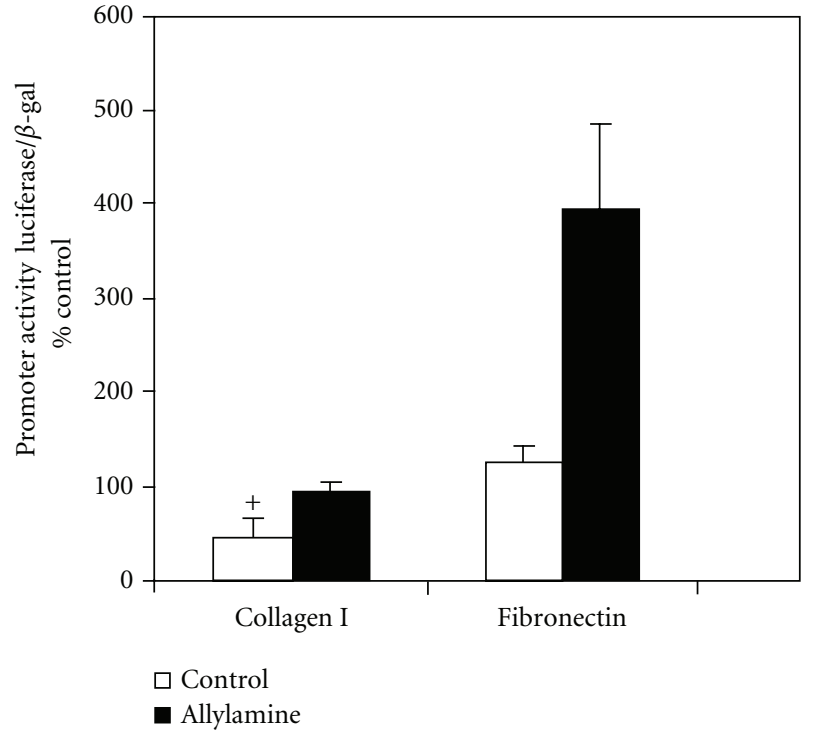

(b)

FIGURE 6: Activity of osteopontin promoter-luciferase constructs in control and allylamine cells seeded on different matrices. Control and allylamine cells were seeded at equivalent densities on collagen I, fibronectin, and laminin, and allowed to recover for 8 hours. Cultures were then transfected with the rat osteopontin promoter $(2094 \mathrm{rOPNpr})$ in a luciferase vector panel (a), and a full length construct in which the NF- $\kappa \mathrm{B}$ site was mutated (NF- $\kappa \mathrm{Bx}$ rOPNpr) panel (b). These mutants are denoted VDREx rOPNPr, AP- $1 \mathrm{x}$ rOPNpr, NF- $\kappa$ Bx rOPNpr, USF1x rOPNpr, USF2x rOPNpr, and USF3x rOPNpr. $\square$ : control, $\mathbf{\square}$ : allylamine; $*$ indicates significantly different from control, + indicates significantly different from 2094 rOPNpr in same cell type on same seeding matrix $(P<0.05)$. Similar results were seen in multiple experiments.

$o p n$ is regarded as a critical modulator of atherogenesis, but little is known about the regulation of opn promoter in vSMCs. Interestingly, upstream stimulatory factor (USF1) has been implicated in injury-induced opn expression [36], while AP-1 has been implicated in regulation of opn [18], possibly as a result of increased ERK1/ERK2 activity [37]. Thus, NF- $\kappa \mathrm{B}$ may serve as a regulator of the opn promoter in trans, an effect clearly dependent on the extracellular matrix. The repressor activity of NF- $\kappa \mathrm{B}$ has been linked to the formation of $\mathrm{p} 50 / \mathrm{p} 52$ heterodimers or $\mathrm{p} 50 / \mathrm{p} 50$ homodimers $[38,39]$, a correlation that is consistent with the higher levels of these proteins observed in allylamine cells compared to controls, and the influence of fibronectin on patterns of protein expression. Since p50 and p52 contain no transactivation domain, hetero- and homodimers of these Rel proteins can bind NF- $\kappa \mathrm{B}$ binding sites to inhibit transactivation $[39,40]$. Indeed, a study of NF- $\kappa \mathrm{B}$ binding sites suggests a high affinity of repressive NF- $\kappa$ B dimers for the $o p n$ promoter sequence. Interestingly, cooperation between USF- 1 and NF- $\kappa$ B in the negative regulation of $o p n$ promoter activity is possible since mutation of either binding site restored promoter activity in allylamine cells to control levels, and cooperativity between these transcription factors in binding to nucleosomes has been described [41].

\section{Acknowledgments}

This work was supported in part by grants from the National Heart, Lung, and Blood Institute (HL62539 to KSR and EW), and the National Institute of Environmental Health Sciences
(ES04849, ES014443 and ES09106 to KSR). E. Spencer Williams was supported in part by a Covance Corporation Graduate Student Fellowship.

\section{References}

[1] R. Ross, "Cellular and molecular studies of atherogenesis," Atherosclerosis, vol. 131, pp. S3-S4, 1997.

[2] A. C. Newby and A. B. Zaltsman, "Molecular mechanisms in intimal hyperplasia," Journal of Pathology, vol. 190, no. 3, pp. 300-309, 2000.

[3] C. Espinola-Klein, H. J. Rupprecht, S. Blankenberg et al., "Impact of infectious burden on extent and long-term prognosis of atherosclerosis," Circulation, vol. 105, no. 1, pp. 15-21, 2002.

[4] R. E. Albert, M. Vanderlaan, F. J. Burns, and M. Nishizumi, "Effect of carcinogens on chicken atherosclerosis," Cancer Research, vol. 37, no. 7, pp. 2232-2235, 1977.

[5] K. S. Ramos, Y. Zhang, D. N. Sadhu, and R. S. Chapkin, "The induction of proliferative vascular smooth muscle cell phenotypes by benzo(a)pyrene is characterized by upregulation of inositol phospholipid metabolism and c-Ha-ras gene expression," Archives of Biochemistry and Biophysics, vol. 332, no. 2, pp. 213-222, 1996.

[6] R. Ross, "The pathogenesis of atherosclerosis: a perspective for the 1990s," Nature, vol. 362, no. 6423, pp. 801-809, 1993.

[7] J. Thyberg and A. Hultgardh-Nilsson, "Fibronectin and the basement membrane components laminin and collagen type IV influence the phenotypic properties of subcultured rat aortic smooth muscle cells differently," Cell and Tissue Research, vol. 276, no. 2, pp. 263-271, 1994. 
[8] K. S. Ramos and L. R. Cox, "Aortic endothelial and smooth muscle cell cultures," in Methods in Toxicology: In Vitro Biological Sytems, chapter 14, pp. 159-168, Academic Press, New York, NY, USA, 1993.

[9] G. A. Lyles and I. Singh, "Vascular smooth muscle cells: a major source of the semicarbazide-sensitive amine oxidase of the rat aorta," Journal of Pharmacy and Pharmacology, vol. 37, no. 9, pp. 637-643, 1985.

[10] C. R. Partridge, E. S. Williams, R. Barhoumi et al., "Novel genomic targets in oxidant-induced vascular injury," Journal of Molecular and Cellular Cardiology, vol. 38, no. 6, pp. 983996, 2005.

[11] L. R. Cox and K. Ramos, "Allylamine-induced phenotypic modulation of aortic smooth muscle cells," Journal of Experimental Pathology, vol. 71, no. 1, pp. 11-18, 1990.

[12] K. S. Ramos, "Redox regulation of c-Ha-ras and osteopontin signaling in vascular smooth muscle cells: implications in chemical atherogenesis," Annual Review of Pharmacology and Toxicology, vol. 39, pp. 243-265, 1999.

[13] M. Karin and Y. Ben-Neriah, "Phosphorylation meets ubiquitination: the control of NF- $\kappa \mathrm{B}$ activity, Annual Review of Immunology, vol. 18, pp. 621-663, 2000.

[14] J. Anrather, G. Racchumi, and C. Iadecola, "cis-Acting element-specific transcriptional activity of differentially phosphorylated nuclear factor- $\kappa \mathrm{B}$," Journal of Biological Chemistry, vol. 280, no. 1, pp. 244-252, 2005.

[15] N. D. Perkins, "Achieving transcriptional specificity with NF$\kappa \mathrm{B}$," International Journal of Biochemistry and Cell Biology, vol. 29, no. 12, pp. 1433-1448, 1997.

[16] N. D. Perkins, "The Rel/NF- $\kappa$ B family: friend and foe," Trends in Biochemical Sciences, vol. 25, no. 9, pp. 434-440, 2000.

[17] D. T. Denhardt, M. Noda, A. W. O’Regan, D. Pavlin, and J. S. Berman, "Osteopontin as a means to cope with environmental insults: regulation of inflammation, tissue remodeling, and cell survival," Journal of Clinical Investigation, vol. 107, no. 9, pp. 1055-1061, 2001.

[18] M. Bidder, J. S. Shao, N. Charlton-Kachigian, A. P. Loewy, C. F. Semenkovich, and D. A. Towler, "Osteopontin transcription in aortic vascular smooth muscle cells is controlled by glucoseregulated upstream stimulatory factor and activator protein-1 activities," Journal of Biological Chemistry, vol. 277, no. 46, pp. 44485-44496, 2002.

[19] J. Golledge, M. McCann, S. Mangan, A. Lam, and M. Karan, "Osteoprotegerin and osteopontin are expressed at high concentrations within symptomatic carotid atherosclerosis," Stroke, vol. 35, no. 7, pp. 1636-1641, 2004.

[20] R. Ohmori, Y. Momiyama, H. Taniguchi et al., "Plasma osteopontin levels are associated with the presence and extent of coronary artery disease," Atherosclerosis, vol. 170, no. 2, pp. 333-337, 2003.

[21] Å. Ström, A. Franzén, C. Wängnerud, A.-K. Knutsson, D. Heinegård, and A. Hultgårdh-Nilsson, "Altered vascular remodeling in osteopontin-deficient atherosclerotic mice," Journal of Vascular Research, vol. 41, no. 4, pp. 314-322, 2004.

[22] E. Wilson, A. R. Parrish, C. M. Bral, E. S. Williams, and K. S. Ramos, "Collagen suppresses the proliferative phenotype of allylamine-injured vascular smooth muscle cells," Atherosclerosis, vol. 162, no. 2, pp. 289-297, 2002.

[23] A. R. Parrish and K. S. Ramos, "Differential processing of osteopontin characterizes the proliferative vascular smooth muscle cell phenotype induced by allylamine," Journal of Cellular Biochemistry, vol. 65, no. 2, pp. 267-275, 1997.
[24] J. J. Lalich, "Coronary artery hyalinosis in rats fed allylamine," Experimental and Molecular Pathology, vol. 10, no. 1, pp. 1426, 1969.

[25] J. Barnoya and S. A. Glantz, "Cardiovascular effects of secondhand smoke: nearly as large as smoking," Circulation, vol. 111, no. 20, pp. 2684-2698, 2005.

[26] P. Kovacic and L. A. Thurn, "Cardiovascular toxicity from the perspective of oxidative stress, electron transfer, and prevention by antioxidants," Current Vascular Pharmacology, vol. 3, no. 2, pp. 107-117, 2005.

[27] K. Brand, S. Page, G. Rogler et al., "Activated transcription factor nuclear factor-kappa B is present in the atherosclerotic lesion," Journal of Clinical Investigation, vol. 97, no. 7, pp. 1715-1722, 1996.

[28] T. Bourcier, G. Sukhova, and P. Libby, “The nuclear factor $\kappa$ B signaling pathway participates in dysregulation of vascular smooth muscle cells in vitro and in human atherosclerosis," Journal of Biological Chemistry, vol. 272, no. 25, pp. 1581715824, 1997.

[29] A. C. Newby, "Molecular and cell biology of native coronary and vein-graft atherosclerosis: regulation of plaque stability and vessel-wall remodelling by growth factors and cellextracellular matrix interactions," Coronary Artery Disease, vol. 8, no. 3-4, pp. 213-224, 1997.

[30] K. A. McCullagh and G. Balian, "Collagen characterisation and cell transformation in human atherosclerosis," Nature, vol. 258, no. 5530, pp. 73-75, 1975.

[31] E. R. Andreeva, I. M. Pugach, and A. N. Orekhov, "Collagensynthesizing cells in initial and advanced atherosclerotic lesions of human aorta," Atherosclerosis, vol. 130, no. 1-2, pp. 133-142, 1997.

[32] U. Hedin, B. A. Bottger, E. Forsberg, S. Johansson, and J. Thyberg, "Diverse effects of fibronectin and laminin on phenotypic properties of cultured arterial smooth muscle cells," Journal of Cell Biology, vol. 107, no. 1, pp. 307-319, 1988.

[33] S. A. Jones, J. L. Patterson, J.-T. Chao, K. S. Ramos, and E. Wilson, "Modulation of cyclin dependent kinase inhibitor proteins and ERK1/2 activity in allylamine-injured vascular smooth muscle cells," Journal of Cellular Biochemistry, vol. 91, no. 6, pp. 1248-1259, 2004.

[34] S. Miyamoto, M. J. Schmitt, and I. M. Verma, "Qualitative changes in the subunit composition of $\kappa \mathrm{B}$-binding complexes during murine B-cell differentiation," Proceedings of the National Academy of Sciences of the United States of America, vol. 91, no. 11, pp. 5056-5060, 1994.

[35] J. Roy, P. K. Tran, P. Religa et al., "Fibronectin promotes cell cycle entry in smooth muscle cells in primary culture," Experimental Cell Research, vol. 273, no. 2, pp. 169-177, 2002.

[36] S. Rocha, A. M. Martin, D. W. Meek, and N. D. Perkins, "p53 represses cyclin D1 transcription through down regulation of Bcl-3 and inducing increased association of the p52 NF- $\kappa \mathrm{B}$ subunit with histone deacetylase 1," Molecular and Cellular Biology, vol. 23, no. 13, pp. 4713-4727, 2003.

[37] S. Moses, A. Franzén, C. Lövdahl, and A. Hultgårdh-Nilsson, "Injury-induced osteopontin gene expression in rat arterial smooth muscle cells is dependent on mitogen-activated protein kinases ERK1/ERK2," Archives of Biochemistry and Biophysics, vol. 396, no. 1, pp. 133-137, 2001.

[38] I. A. Udalova, A. Richardson, A. Denys et al., "Functional consequences of a polymorphism affecting NF- $\kappa$ B p50-p50 binding to the TNF promoter region," Molecular and Cellular Biology, vol. 20, no. 24, pp. 9113-9119, 2000. 
[39] X. Tong, L. Yin, R. Washington, D. W. Rosenberg, and C. Giardina, "The p50-p50 NF- $\kappa$ B complex as a stimulusspecific repressor of gene activation," Molecular and Cellular Biochemistry, vol. 265, no. 1-2, pp. 171-183, 2004.

[40] S. Grundström, P. Anderson, P. Scheipers, and A. Sundstedt, "Bcl-3 and NF $\kappa$ B p50-p50 homodimers act as transcriptional repressors in tolerant $\mathrm{CD}^{+} \mathrm{T}$ cells," Journal of Biological Chemistry, vol. 279, no. 9, pp. 8460-8468, 2004.

[41] C. C. Adams and J. L. Workman, "Binding of disparate transcriptional activators to nucleosomal DNA is inherently cooperative," Molecular and Cellular Biology, vol. 15, no. 3, pp. 1405-1421, 1995. 


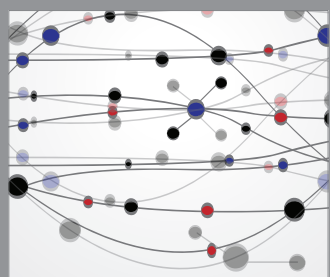

The Scientific World Journal
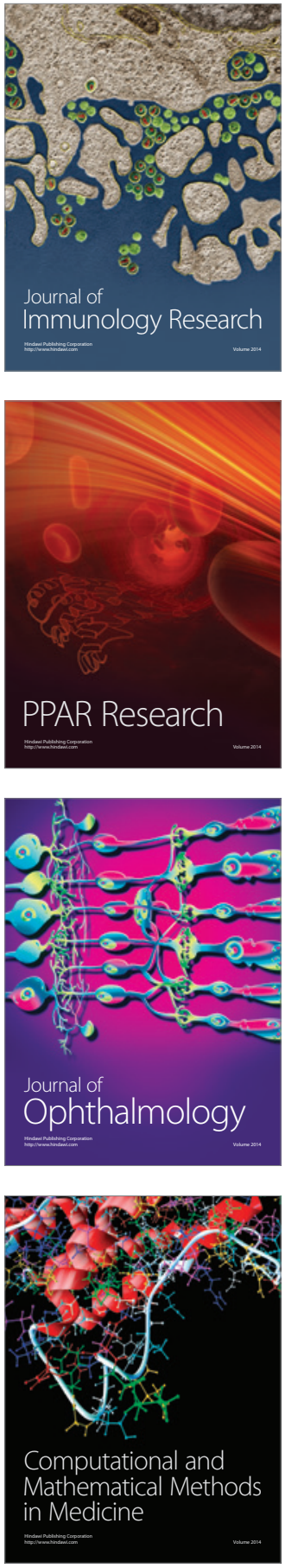

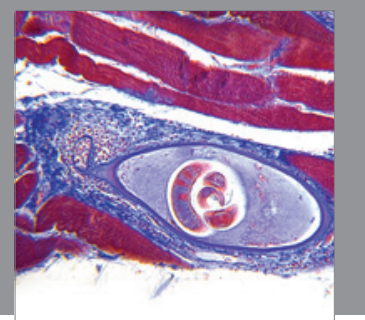

Gastroenterology

Research and Practice
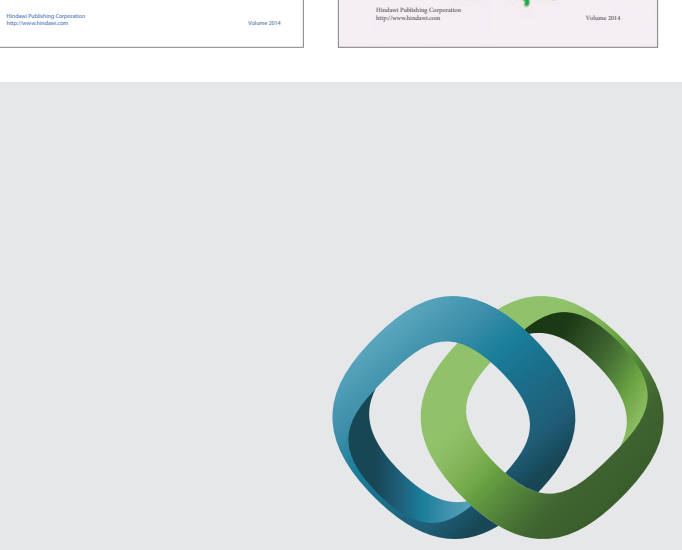

\section{Hindawi}

Submit your manuscripts at

http://www.hindawi.com
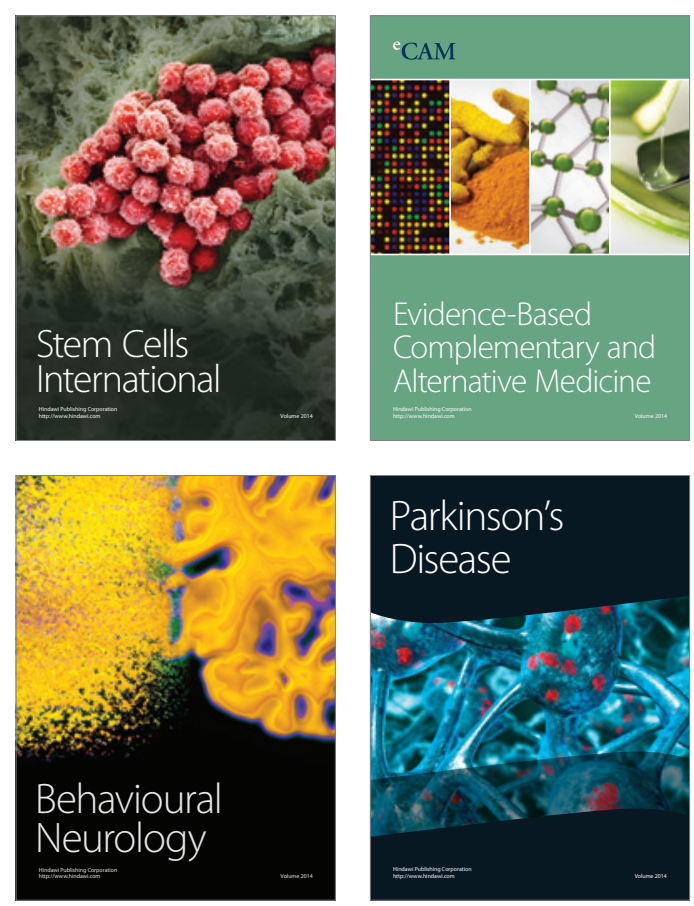

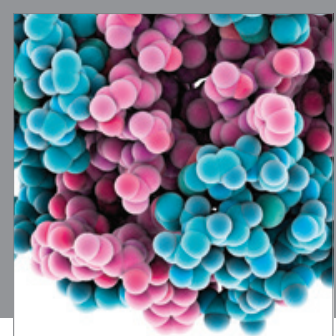

Journal of
Diabetes Research

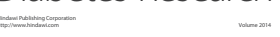

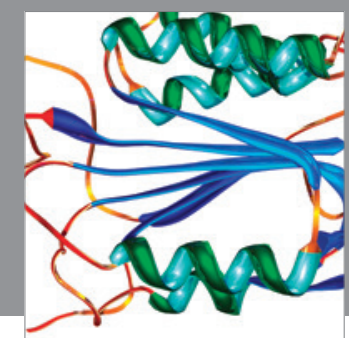

Disease Markers
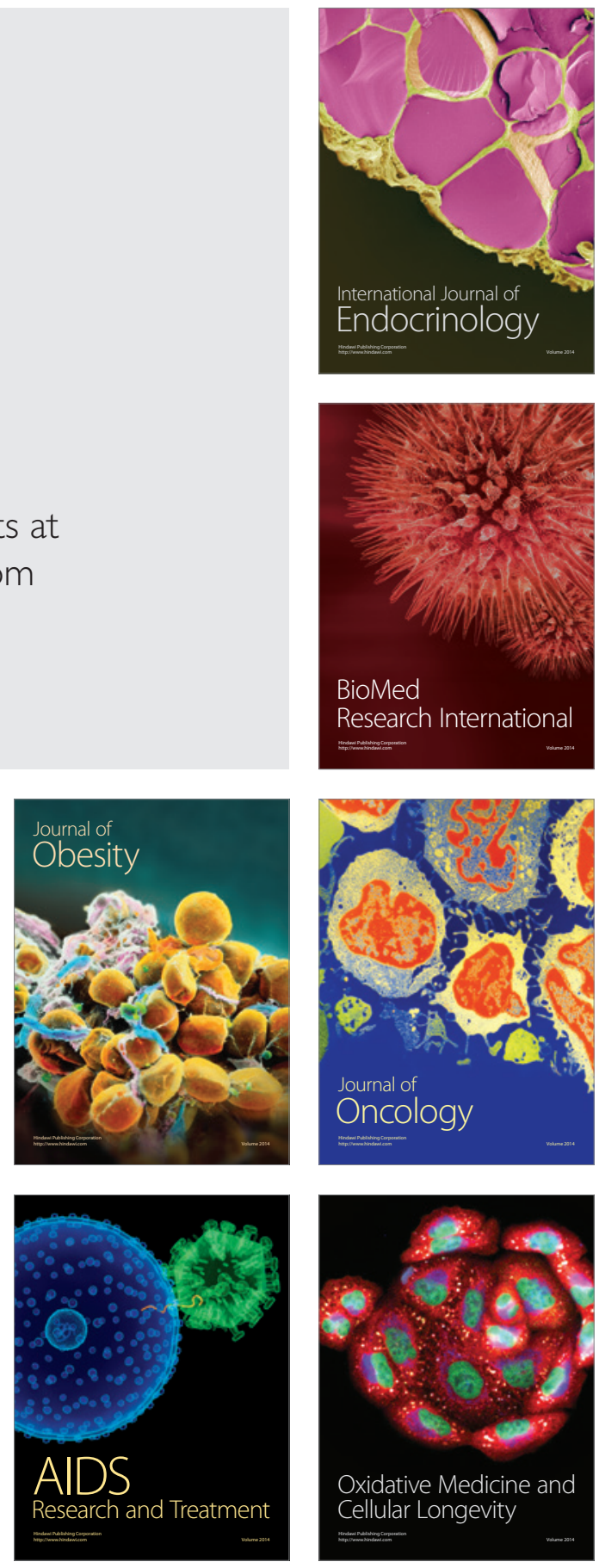